\title{
Micro-core decompression combined with intralesional zoledronic acid as a treatment of osteonecrosis of femoral head: a novel technique
}

\author{
Muhammed Ashraf*, Jyothis George, Ibad Sha I.
}

Department of Orthopaedics, Government T. D. Medical College, Alappuzha, Kerala, India

Received: 13 June 2020

Revised: 03 July 2020

Accepted: 04 July 2020

\section{*Correspondence: \\ Dr. Muhammed Ashraf, \\ E-mail: dr.ashraf.hod@gmail.com}

Copyright: (C) the author(s), publisher and licensee Medip Academy. This is an open-access article distributed under the terms of the Creative Commons Attribution Non-Commercial License, which permits unrestricted non-commercial use, distribution, and reproduction in any medium, provided the original work is properly cited.

\begin{abstract}
Background: Avascular necrosis (AVN)/osteonecrosis of the femoral head is a debilitating condition affecting the hip joint and is one of the most common causes of total hip replacement. The available treatments include pharmacological and surgical options with total hip arthroplasty (THA) being the mainstay of treatment. This present study is a novel technique of combining micro core decompression with intra-lesional bisphosphonate as a treatment for osteonecrosis of the hip.

Methods: A prospective study of 19 hips was done. There were 11 males and 4 females ranging $42-63$ years. Four hips were stage I, ten hips were stage IIA, three hips were stage IIb and two hips were stage III. 16 hips (40\%) had stage IIb and 24 hips $(60 \%)$ had stage III ONFH. The minimum period of follow up was 24 months. All patients were assessed according to the Harris hip score. The operative procedure includes decompressing the avascular area with drilling then injecting the zoledronic acid locally.

Results: The mean preoperative modified Harris hip score in stage I $(n=4)$, stage IIa $(n=10)$, stage IIb $(n=3)$ and stage III $(n=2)$ were 81.9, 72.7, 68.8 and 59.2 respectively. The mean postoperative modified Harris hip score at two years in stage I, stage IIa, stage IIb and stage III were 97.3, 91.1, 88.4 and 82.5 respectively.

Conclusions: We found that the use of micro core-decompression with intra-lesional bisphosphonate will provide higher chances towards hip preservation especially in late cases or cases with larger lesions where core decompression may not be successful.
\end{abstract}

Keywords: Intra-lesional bisphosphonate, Avascular necrosis hip, Hip preservation surgery, Micro core-decompression

\section{INTRODUCTION}

Avascular necrosis (AVN)/osteonecrosis of the femoral head is a debilitating condition affecting the hip joint especially in the younger population and is one of the most common causes of total hip replacement in this age group. ${ }^{1,2}$ The average age of presentation in the Asian population ranges from 20 to 60 years. ${ }^{3}$ Even though exact etiology is still unclear, the risk factors have been well documented in the literature and they are chronic corticosteroid administration, chronic alcohol ingestion, smoking, and various chronic diseases (renal disease, haematological disease, inflammatory bowel disease, post organ transplantation, hypertension, and gout). ${ }^{3-6}$ Clinically early stages of AVN are painless which on progression will result in severe groin associated with limitation of hip movement and collapse of femoral head ultimately leading to end-stage degeneration. . $^{3,6,7}$

Hence early detection and interference are needed to prevent disease progression which is also one of the main treatment goals. 
In the treatment of AVN hip, there is no gold standard. The available treatments include pharmacological and surgical options which are mainly based on categorization into precollapse or early collapse and advanced collapse or osteoarthritis stage. ${ }^{8-10}$ It is documented in the literature that hip preservation surgery in late stages is met with poor outcomes. ${ }^{11}$ Core decompression is commonly practised surgical procedure in the early stages of AVN hip. The procedure reduces the elevated intraosseous pressure in the femoral head leading to increased blood flow thereby promoting new bone formation and healing., $7,9,11$ Bisphosphonates have been indicated in AVN cases up to the stage of early collapse and their property of inhibiting the osteoclastic activity in the osteonecrotic lesion site, thus promoting bone healing and preventing the onset of collapse or fracture of subchondral bone. ${ }^{12,13}$ Commonly studied bisphosphonate in literature is alendronate which is an oral drug and is reported to be effective in reducing the collapse rate over $50 \%$ compared to the placebo groups at doses of $10 \mathrm{mg} /$ day or $70 \mathrm{mg} /$ week. ${ }^{9}$ But there have been no studies in the literature where a bisphosphonate has been administered locally to achieve higher concentration along multiple micro-decompression holes and thereby achieving better bioavailability at the pathological site.

In this study we have hypothesized that a higher concentration of bisphosphonate at the pathological site can bring better results compared to systemic administration where the drug is distributed evenly across the body and added micro-decompression drill holes will also help to reduce intraosseous pressure as well as act as act as channels for intraosseous bisphosphonate injection. We combined two different treatment modality i.e. safe surgical dislocation with micro core decompression combined with intralesional zoledronic acid, to achieve maximum results. No similar technique has been studied previously in the literature.

\section{METHODS}

The study was conducted after receiving ethical clearance from the institutional ethical committee. The study was performed in the department of orthopaedics, government T. D. Medical College, Alappuzha from January 2016 to December 2018. Informed written consent was obtained from all patients. The study population consisted of patients presenting with AVN of femoral head in Ficat arlet stage I and IIA. 12 stage IIB and III patients are included if their hip flexions movements are not restricted more than $50 \%$. We excluded patients with history previous hip trauma, sickle cell anemia, local bone diseases like osteogenesis imperfecta and neoplastic pathology. Patients with a minimum 2 years follow up were included in the study.

Patients were interviewed, examined, and a base X-ray was taken to confirm the diagnosis and to compare it with the results after surgery. Pre-operative operative MRI was taken to confirm the stage of disease process in AVN hip. After doing preanesthetic evaluation and fitness, patients were taken up for surgical procedure. Intra-operative findings along with any complications were documented. Post-operatively patients were followed up every 3 months for the first year, every 6 months for the second year, and yearly thereafter. Results were determined by the change in Harris hip scores (HHS) from preoperative evaluation to the last follow-up visit. ${ }^{7}$ A total of 19 hips of 15 patients were selected for the study of which 2 cases ( 3 hips) were lost for follow-up and hence not included in the final results.

\section{Surgical procedure}

The patient is placed under general anaesthesia and is positioned lateral decubitus followed by prepping and draping in an aseptic manner. A linear incision cantered over the greater trochanter is made. Fascia lata is incised and Gibsons interval lying between gluteus medius and maximus is identified and retracted. Trochanteric bursa is incised followed by identification of piriformis tendon. Dissection should not go proximal to piriformis and distal to lesser trochanter to avoid injury to the deep branch of MCFA. This is followed by trochanteric flip osteotomy and the greater trochanter was retracted anteriorly along with its muscle attachments (vastus lateralis and the gluteus medius). Gluteus minimus is retracted superiorly to expose the capsule. Z-capsulotomy as described by Ganz is performed to deliver the head anteriorly by flexion-external rotation-adduction. ${ }^{14}$

The femoral head is then inspected thoroughly for any central (loose chondral flaps) and peripheral lesions (cam, osteophytes, labral tear and acetabular erosions). Loose Chondral flaps in the femoral head surface denotes the potential avascular areas. Identification of these areas are important as micro core decompression and bisphosphonate infiltration should be concentrated here. For micro core decompression multiple holes are made with $3.5 \mathrm{~mm}$ drill bit until fresh bleeding spots are observed. Bleeding spots observed indicates retained vascularity of femoral head as well communication of avascular area to healthy normal bony trabeculae. Peripheral osteophytes and cam lesions are trimmed using rongeur and osteotome. Thorough saline lavage is done to remove any loose bodies and debris. This followed by thorough infiltration of zoledronic acid prepared by mixing $4 \mathrm{mg}$ ( 2 vials) diluted in $100 \mathrm{ml} \mathrm{NS}$ into the micro decompressed holes. Femoral head is then anatomically relocated into the acetabulum (Figure 1). Capsular repair is followed by stability assessment and trochanteric fixation with $4 \mathrm{~mm}$ cancellous screw. If in case the trochanteric flip thickness is less than $1 \mathrm{~cm}$ stainless steel wires are utilised for stabilisation. Serial soft tissue closure done after putting negative suction drain. Post-operatively the patient is started on non-weight bearing ambulation and weight bearing after 6 weeks.

The data is entered in Microsoft excel and analysed using SPSS (statistical package for social sciences) software released by IBM corp. Released 2012. The quantitative 
variables are expressed as mean and standard deviation and the qualitative variables are expressed as proportions. Parametric (student's t-test) and nonparametric (MannWhitney U test) statistical tests were used to compare the final results.

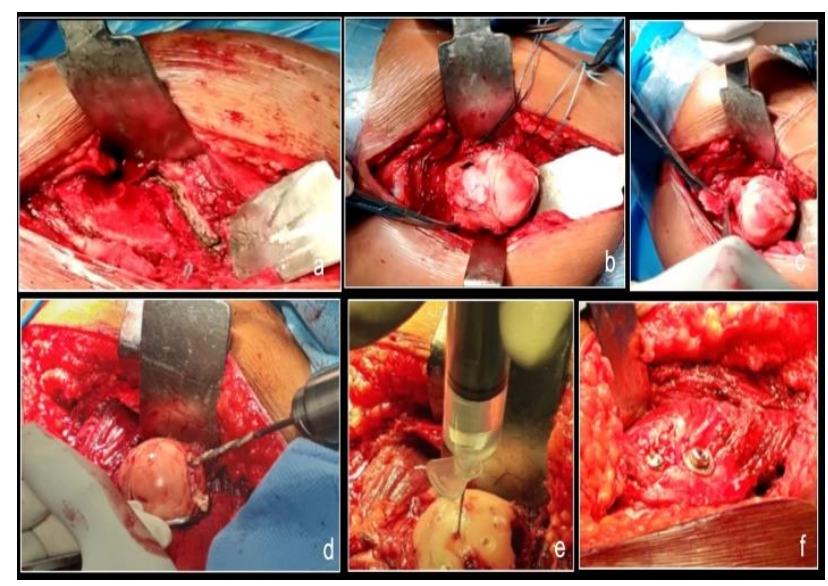

Figure 1: Intra-operative images (a) Z-capsulotomy, (b) safe surgical dislocation, (c) osteophyte removal from periphery, (d) micro core decompression, (e) intra-lesional zolendronic acid infiltration, and (f) trochanteric repair.

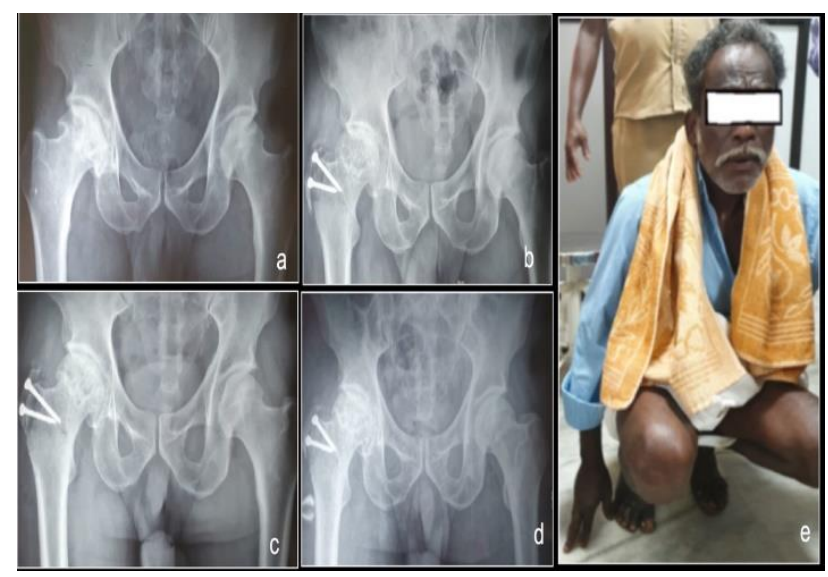

Figure 2: (a) pre-operative radiograph, (b) 6 months follow-up, (c) 1-year follow-up, and (d) 2 years followup.

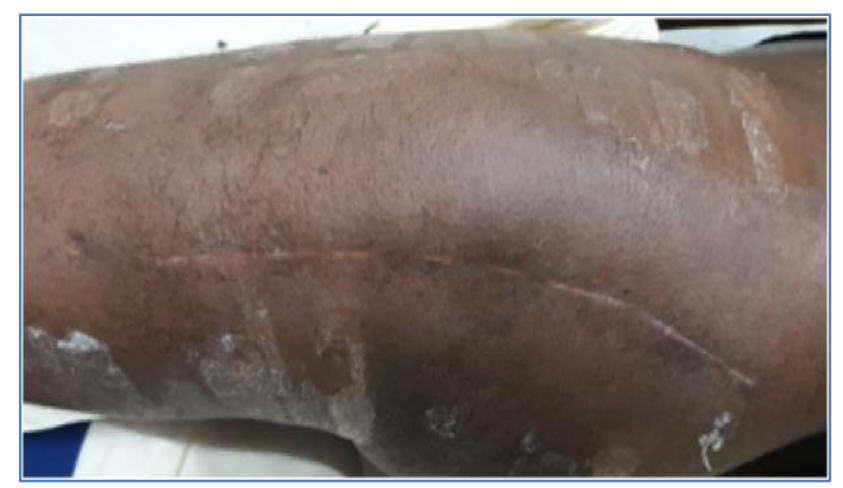

Figure 3: Trochanteric bursitis.

\section{RESULTS}

A total of 15 cases and 19 hips were included in the study during the study period of 2 years (2016-2018). Average age of the study population was 54.3 years ranging between $42-63$ years. Of the 15 cases, 11 cases were males $(73.3 \%)$ and the remaining 4 cases were females. Average duration of symptoms were 16.7 months (range 6-27 months). Regarding the risk factors of AVN, history of steroid intake was present $33.3 \%$, smoking in $60 \%$ cases and alcohol abuse was present in $53.3 \%$. In four patients no identifiable risk factors were detected. Systemic comorbidities were present in 9 out of 15 cases of which 6 had diabetes and hypertension, 2 had COPD and 1 had coronary artery disease) (Table 1-3).

Table 1: Distribution of patients showing general characteristics, habits and co-morbidities $(n=15)$.

\begin{tabular}{|c|c|c|c|}
\hline Variables & & Frequency & Percent \\
\hline \multirow{2}{*}{ Sex } & Male & 11 & 73.3 \\
\hline & Female & 4 & 26.7 \\
\hline \multirow{3}{*}{ Side affected } & Right & 11 & 57.89 \\
\hline & Left & 8 & 42.11 \\
\hline & Bilateral & 4 & \\
\hline \multirow{2}{*}{ Steroid intake } & Yes & 5 & 33.0 \\
\hline & No & 10 & 67.0 \\
\hline \multirow{2}{*}{ Smoking } & Yes & 9 & 60.0 \\
\hline & No & 6 & 40.0 \\
\hline \multirow{2}{*}{ Alcohol use } & Yes & 8 & 53.3 \\
\hline & No & 7 & 46.7 \\
\hline Trauma & No & 42 & 100.0 \\
\hline \multirow{7}{*}{$\begin{array}{l}\text { Concomitant } \\
\text { disease }\end{array}$} & CAD & 1 & 6.7 \\
\hline & CKD & 0 & \\
\hline & COPD & 2 & 13.3 \\
\hline & DLP & 0 & \\
\hline & $\mathrm{DM}$ & 6 & 40.0 \\
\hline & HTN & 6 & \\
\hline & NIL & 6 & 40.0 \\
\hline
\end{tabular}

Of the 19 studied hips, 11 hips were right and remaining 8 were left sided. There were four bilateral cases among which one caseload was lost to follow-up and hence not included in final statistical analysis. Four hips were stage I, ten hips were stage IIA, three hips were stage IIb and two hips were stage III. The stage III hips included in study has retained hip movements of more than $50 \%$.

Mean pre-operative range of movements were flexion;

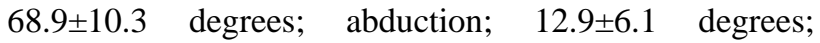
adduction; $6.7 \pm 3.1$ degrees; arc of rotation; $45.3 \pm 15.1$ degrees. Mean duration of hospital stay was 7.5 \pm 3.2 days ranging between 5-14 days. Except for 2 patients (one bilateral) all cases were followed up for minimum 2 years (Figure 2).

The mean pre-operative modified HHS in stage $I(n=4)$, stage IIa $(n=10)$, stage IIb $(n=3)$ and stage III $(n=2)$ were 
$81.9,72.7,68.8$ and 59.2 respectively. The mean postoperative modified HHS for stage I at 6 months, 1 year and 2 years were $89.6,92.6$ and 97.3 respectively and was statistically significant $(\mathrm{p}<0.021$ at 2 years). The mean postoperative modified HHS for stage IIa at 6 months, 1 year and 2 years were 80.2, 87.1 and 91.1 respectively and was statistically significant ( $\mathrm{p}<0.001$ at 2 years). The mean post-operative modified HHS for stage IIb at 6 months, 1 year and 2 years were $79.5,84.6$ and 88.4 respectively and was statistically significant ( $\mathrm{p}<0.032$ at 2 years) (Table 4$)$. The mean postoperative modified HHS for stage III at 6 months, 1 year and 2 years were 72.1, 77.3 and 82.5 respectively and was statistically significant $(\mathrm{p}<0.019$ at 2 years). Radiological evaluation with $\mathrm{X}$-ray at follow ups showed gradual restoration of femoral head morphology, increase in bone density and prevention of collapse progression.

Table 2: Complications developed by subjects at 6, 12 and 24 months.

\begin{tabular}{|llll|}
\hline Age (in years) & Frequency & Percent \\
\hline \multirow{2}{*}{ 6 months } & $\begin{array}{l}\text { Superficial } \\
\text { infection }\end{array}$ & 2 & 13.3 \\
\cline { 2 - 4 } & Nil & 13 & 86.7 \\
\hline \multirow{2}{*}{ 1-year } & $\begin{array}{l}\text { Trochant- } \\
\text { eric bursitis }\end{array}$ & 2 & 13.3 \\
\cline { 2 - 4 } & Nil & 13 & 86.7 \\
\hline 2 years & Nil & 15 & 100 \\
\hline
\end{tabular}

Table 3: Descriptive statistics.

\begin{tabular}{|llll|}
\hline Variables & N & Minimum & Maximum \\
\hline Age in years & 15 & 42 & 63 \\
\hline $\begin{array}{l}\text { Duration of } \\
\text { symptoms }\end{array}$ & 15 & 6 & 27 \\
\hline Admission HHS & 15 & 59.2 & 81.9 \\
\hline 6 months HHS & 15 & 72.1 & 89.6 \\
\hline 1-year HHS & 15 & 77.3 & 92.6 \\
\hline 2 years HHS & 15 & 82.5 & 97.3 \\
\hline
\end{tabular}

Table 4: Mean HHS at follow-up.

\begin{tabular}{|lllll|}
\hline Mean HHS & $\begin{array}{l}\text { Stage } \\
\text { I }\end{array}$ & $\begin{array}{l}\text { Stage } \\
\text { IIa }\end{array}$ & $\begin{array}{l}\text { Stage } \\
\text { IIb }\end{array}$ & $\begin{array}{l}\text { Stage } \\
\text { III }\end{array}$ \\
\hline Pre-operative & 81.9 & 72.7 & 68.8 & 59.2 \\
\hline 6 months & 89.6 & 80.2 & 79.5 & 72.1 \\
\hline 1 year & 92.6 & 87.1 & 84.6 & 77.3 \\
\hline 2 years & 97.3 & 91.1 & 88.4 & 82.5 \\
\hline
\end{tabular}

Post-operatively five cases had surgery related complications of which superficial infection in two cases, trochanteric bursitis in two cases and delayed union of trochanter was encountered in one patient (Figure 3). Both cases of superficial infection subside with continued antibiotics for two weeks and wound care. Both patients with trochanteric bursitis had persistent complaints after trial of conservative treatment, hence needed implant removal after trochanteric union. None of the patients developed heterotopic ossification.

\section{DISCUSSION}

Early diagnosis and treatment of osteonecrosis is essential for avoiding the progression of disease and need for hip arthroplasty. Over the last decades multiple treatment modalities have been documented in literature for hip preservation and to delay the progression to THR. These treatments vary with different stages of the disease and there is not yet any ideal treatment for AVN hip. The need for hip preservation is emphasised mainly because of the disadvantages like implant loosening and need for revision surgery especially in young patients. ${ }^{15}$ Hence the current trend in surgical practice is more and more towards hip preservation surgeries. Core decompression was first introduced by Arlet and Ficat in 1964 and they reported "good to very good results" in $90 \%$ of these hips on clinical evaluation and in $79 \%$ on radiographic evaluation. ${ }^{16} \mathrm{~A}$ meta-analysis by Marker et al documented that upto 30\% of hips required THR at 3 years follow-up after core decompression. ${ }^{17}$ Another review by Rajagopal et al also reported the similar rate of conversion to THR and they pointed out that the results were better with stage 1 disease compared to other stages. ${ }^{18}$

The conventional method of core decompression involves single 8-10 $\mathrm{mm}$ core removal to decompress the femoral head but it has been documented to be associated with complications like risk of iatrogenic subtrochanteric fracture, inadequate decompression as well as risk of chondral injury. ${ }^{10,19}$ As an alternative multiple drill hole decompressions has been documented in the literature by different authors. A study by Kim et al compared multiple drilling with single core decompression and reported that statistically significant longer time for progression to collapse with multiple drilling techniques. ${ }^{20}$ Similar results with multiple drilling were also obtained by other authors. ${ }^{21,22}$ In our study we achieved micro core decompression through multiple drilling and also noted that decompression can be achieved efficiently with minimal disruption of structural integrity of femoral head.

Over the period of time, multiple authors have documented different methods to augment the results associated with core decompression. This includes use of BMPs, mesenchymal stem cells (MSC), bone grafting, nonvascularized cortical grafts, iliac artery pedicled graft, vascularised fibular graft etc. ${ }^{9,13}$ MSC from adult bone marrow are multipotent and have been documented to influence the bone repair in AVN hip. Early functional and radiological results associated with use of MSC with core decompression has been reported to be encouraging even though the results of long term follow up is yet to be available. ${ }^{23,24}$ Limitation associated with routine use of MSC is its isolation, purification and culture needs special machineries which may be available only at selected centres. 
Use of vascularised fibular graft has been associated with mixed results in literature. Zhang et al reported postoperative improvement HHS to 94.4, 85.7, and 76.4 from 78.5, 69.3, and 58.4 in Steinberg grades II, III, and IV respectively. ${ }^{25}$ But some authors suggest poor prognosis of vascularised fibular graft in avascular lesions associated with steroid use. ${ }^{26}$ More the efficiency of the same in late stages of AVN has not been properly studied as most available studies composed of early stages. The risk of arterial insufficiency associated with kinking or strangulation of pedicle along with added technical expertise needed for procedure contributes to the limitation in using this technique.

The efficacy of oral bisphosphonates in AVN hip has been documented by multiple studies in the literature. Their property of inhibiting osteoclastic activity in the avascular lesion promotes bone healing as well as prevention of progression to subchondral fracture in early cases and delays collapse in advanced cases. ${ }^{27-31}$ In a study by Agarwala et al, the authors concluded that favourable alteration can be made in the natural history of untreated ON with more than $70 \%$ collapse rate. ${ }^{27}$ Similar results were documented by another author who studied 53 hips followed up for 10 years after 3 years of weekly bisphosphonate. $^{28}$

A randomized control trial evaluating the efficacy of oral alendronate observed a radiographic progression of $80 \%$ in the control group compared with $14 \%$ in the treatment group. ${ }^{32}$ Most of the previous study on the efficacy of bisphosphonate in AVN, oral administration was followed. In our study we opted for local infiltration of bisphosphonate and the rationale behind was the property of bisphosphonate to get rapidly absorbed onto bone surface and higher concentration achieved locally compared to other forms of administration. In oral as well intravenous administration around $50 \%$ absorbed drug is excreted unchanged through the kidney and the equal distribution of the remaining drug in the circulation results in failure to achieve maximum concentration at the desired site. $^{33}$

In our study we used a novel technique of microcore decompression combined with local bisphosphonate administration. To our knowledge the technique has not been documented in the literature. At 2 year follow up the HHS improved to 97.3, 91.1, 88.4 and 82.5 from preoperative HHS of 81.9, 72.7, 68.8 and 59.2 for stage I, stage IIa, stage IIb and stage III respectively. A study on core decompression and bone grafting done by Shah et al (2015) on 28 hips upto stage IIb reported good or excellent outcome in 19 hips had good or excellent outcome; fair outcome in 1 hip and 8 hips had poor result. ${ }^{28}$ The success rate was higher upto grade IIA and for grade IIB the success rate was only $50 \%$. Wei et al studied the effect of core decompression combined fibular allograft and autologous bone grafting and at mean follow-up of 24 months excellent and good results were obtained in $93.3 \%$ of cases in stage II, and $87 \%$ in stages III with a survivorship of $81 \%$ in all cases. ${ }^{34}$
There are some limitations to our study. This includes smaller sample size, shorter duration of follow-up, absence of control group and inadequate representation of bilateral cases. A randomized control study with higher sample size can verify the further results. We also did not correlate the results of the study with the etiology and size of the lesion. All surgeries were done by a single surgeon who had vast experience in hip surgery, hence no approach related complications were encountered.

\section{CONCLUSION}

The preliminary results of the newer surgical technique incorporating micro-core decompression with local bisphosphonate infiltration has been encouraging and will provide higher chances towards hip preservation especially in late cases or cases with larger lesions where core decompression may not be successful.

Funding: No funding sources

Conflict of interest: None declared

Ethical approval: The study was approved by the institutional ethics committee

\section{REFERENCES}

1. Baig SA, Baig MN. Osteonecrosis of the Femoral Head: Etiology, Investigations, and Management. Cureus. 2018;10(8):3171.

2. Kakaria HL, Sharma AK, Sebastian B. Total Hip Replacement in Avascular Necrosis of Femoral Head. Med J Armed Forces India. 2005;61(1):33-5.

3. Vardhan H, Tripathy SK, Sen RK, Aggarwal S, Goyal T. Epidemiological Profile of Femoral Head Osteonecrosis in the North Indian Population. Indian J Orthop. 2018;52(2):140-6.

4. Boskey AL, Raggio CL, Bullough PG, Kinnett JG. Changes in the bone tissue lipids in persons with steroid and alcohol-induced osteonecrosis. Clin Orthop Relat Res. 1983;172:289-95.

5. Matsuo K, Hirohata T, Sugioka Y, Ikeda M, Fukuda A. Influence of alcohol intake, cigarette smoking, and occupational status on idiopathic osteonecrosis of the femoral head. Clin Orthop Relat Res. 1988;234:11523.

6. Koo KH, Kim R, Kim YS, Ahn IO, Cho SH, Song $\mathrm{HR}$, et al. Risk period for developing osteonecrosis of the femoral head in patients on steroid treatment. Clin Rheumatol. 2002;21:299-303.

7. Angeler MJ, Gianakos A, Villa J, Ni A, Lane J. Current concepts on osteonecrosis of the femoral head. World J Orthop. 2015;6:590-601.

8. Lieberman JR, Berry DJ, Mont MA, Aaron RK, Callaghan JJ, Rajadhyaksha AD, et al. Osteonecrosis of the hip: management in the 21 st century. Instr Course Lect. 2003;52:337-55.

9. Sen RK. Management of avascular necrosis of femoral head at pre-collapse stage. Indian J Orthop. 2009;43:6-16. 
10. Mont MA, Hungerford DS. Non-traumatic avascular necrosis of the femoral head. J Bone Joint Surg Am. 1995;77:459-74.

11. Dayan AY, Chang C, Greenspan A, Shoenfeld Y, Gershwin ME. Pathogenesis and natural history of osteonecrosis. Seminars Arthritis Rheumatism. 2002;32(2):94-124.

12. Chen CH, Chang JK, Lai KA, Hou SM, Chang CH, Wang GJ. Alendronate in the prevention of collapse of the femoral head in nontraumatic osteonecrosis: a two-year multicenter, prospective, randomized, double-blind, placebo-controlled study. Arthritis Rheum. 2012;64:1572-8.

13. Peled E, Bejar J, Barak M, Orion E, Norman D. Core decompression and alendronate treatment of the osteo-necrotic rat femoral head: computer-assisted analysis. Int J Exp Pathol. 2013;94:212-6.

14. Ganz R, Gill TJ, Gautier E, Ganz K, Krugel N, Berlemann U. Surgical dislocation of the adult hip a technique with full access to the femoral head and acetabulum without the risk of avascular necrosis. J Bone Joint Surg Br. 2001;83(8):1119-24.

15. Polkowski GG, Callaghan JJ, Mont MA, Clohisy JC. Total Hip Arthroplasty in the Very Young Patient. J Am Academy Orthopaedic Surg. 2012;20(8):487-97.

16. Arlet J, Ficat RP. Forage-biopsie de la tete femorale dans 1'osteonecrose primitive; Observations histopathologiques portant sur huit foranes. Rev Rhum Ed Fr. 1964;31:257-64.

17. Marker DR, Seyler TM, Ulrich SD, Srivastava S, Mont MA. Do modern techniques improve core decompression outcomes for hip osteonecrosis. Clin Orthop Relat Res. 2008;466(5):1093.

18. Rajagopal M, Samora BJ, Ellis TJ. Efficacy of core decompression as treatment for osteonecrosis of the hip: a systematic review. Hip Int J Clin Exp Res Hip pathol Ther. 2012;22(5):489.

19. Mohanty SP, Singh KA, Kundangar R, Shankar V. Management of non-traumatic avascular necrosis of the femoral head: a comparative analysis of the outcome of multiple small diameter drilling and core decompression with fibular grafting. Musculoskeletal Surg. 2017;101:59-66.

20. Kim SY, Kim DH, Park IH. Multiple drilling compared with core decompression for the treatment of osteonecrosis of the femoral head. J Bone Joint Surg Br. 2004;86:149.

21. Song WS, Yoo JJ, Kim YM, Kim HJ. Results of Multiple Drilling Compared with Those of Conventional Methods of Core Decompression. Clin Orthopaedics Related Res. 2007;454:139-46.

22. Li J, Li ZL, Zhang H, Su XZ, Wang KT, Yang YM. Long-term Outcome of Multiple Small-diameter Drilling Decompression Combined with Hip Arthroscopy versus Drilling Alone for Early Avascular Necrosis of the Femoral Head. Chinese Med J. 2017;130(12):1435-40.

23. Müller I, Vaegler M, Holzwarth C, Tzaribatchev N, Pfister SM, Schutt B, et al. Secretion of angiogenic proteins by human multipotent mesenchymal stromal cells and their clinical potential in the treatment of avascular osteonecrosis. Leukemia. 2008;22:205461.

24. Kawate K, Yajima H, Ohgushi H, Kotobuki N, Sugimoto K, Ohmura T, et al. Tissue-engineered approach for the treatment of steroid-induced osteonecrosis of the femoral head: Transplantation of autologous mesenchymal stem cells cultured with beta-tricalcium phosphate ceramics and free vascularized fibula. Artif Organs. 2006;30:960-2.

25. Zhang C, Zeng B, Xu Z, Song W, Shao L, Jing D, et al. Treatment of femoral head necrosis with free vascularized fibula grafting: a preliminary report. Microsurgery. 2005;25:305-9.

26. Fang T, Zhang EW, Sailes FC, McGuire RA, Lineaweaver WC, Zhang F. Vascularized fibular grafts in patients with avascular necrosis of femoral head: A systematic review and meta-analysis. Arch Orthop Trauma Surg. 2013;133:1-10.

27. Agarwala S, Jain D, Joshi VR, Sule A. Efficacy of alendronate, a bisphosphonate, in the treatment of AVN of the hip: a prospective open-label study. Rheumatology. 2005;44:352-9.

28. Agarwala S, Shah SB. Ten-year follow-up of avascular necrosis of femoral head treated with alendronate for 3 years. J Arthroplasty. 2011;26:1128-34.

29. Nishii T, Sugano N, Miki H, Hashimoto J, Yoshikawa H. Does alendronate prevent collapse in osteonecrosis of the femoral head. Clin Orthop Relat Res. 2006;443:273-9.

30. Chen CH, Chang JK, Lai KA, Hou SM, Chang CH, Wang GJ. Alendronate in the prevention of collapse of the femoral head in nontraumatic osteonecrosis: A two-year multicenter, prospective, randomized, double-blind, placebo-controlled study. Arthritis Rheum. 2012;64:1572-8.

31. Lai KA, Shen WJ, Yang CY, Shao CJ, Hsu JT, Lin $\mathrm{RM}$. The use of alendronate to prevent early collapse of the femoral head in patients with nontraumatic osteonecrosis. A randomized clinical study. J Bone Joint Surg Am. 2005;87:2155-9.

32. Wang JA. Evidence for Using Alendronate to Treat Adult Avascular Necrosis of the Femoral Head: A Systematic Review. Med Sci Monitor. 2014;20:2439-47.

33. Kumar V, Shahi AK. Nitrogen containing bisphosphonates associated osteonecrosis of the jaws: A review for past 10 years literature. Dent Res J. 2014;11(2):147-53.

34. Wei, Biao, Ge, Xiang. Treatment of osteonecrosis of the femoral head with core decompression and bone grafting. Hip Int J Clin Experimental Res Hip Pathology Therapy. 2011;21:206-10.

Cite this article as: Ashraf M, George J, Sha II. Micro-core decompression combined with intralesional zoledronic acid as a treatment of osteonecrosis of femoral head: a novel technique. Int J Res Orthop 2020;6:914-9. 